\title{
An Alternative Sodium Bicarbonate Regimen During Cardiac Arrest and Cardiopulmonary Resuscitation in a Canine Model
}

\author{
Barry E. Bleske, Pharm.D., Ted L. Rice, M.S., and Eric W. Warren, Pharm.D.
}

We evaluated the effect of frequent, early bolus administration of low-dose sodium bicarbonate $\left(\mathrm{NaHCO}_{3}\right)$ on blood gas values during ventricular fibrillation and cardiopulmonary resuscitation (CPR) compared with normal saline and standard bolus doses of $\mathrm{NaHCO}_{3}$. This was a randomized laboratory investigation involving 13 mongrel dogs and 18 experiments ( 5 dogs were used in a crossover manner). Each dog underwent 3 minutes of ventricular fibrillation, followed by 15 minutes of CPR. Animals were randomly assigned to one of three treatments administered early in the resuscitation effort: $\mathrm{NaHCO}_{3}$ $0.5 \mathrm{mEq} / \mathrm{kg}$ at 5,10 , and 15 minutes of ventricular fibrillation $(\mathrm{SB}) ; \mathrm{NaHCO}_{3} \mathrm{I}$ $\mathrm{mEq} / \mathrm{kg}$ at 5 minutes and $0.5 \mathrm{mEq} / \mathrm{kg}$ at 15 minutes of fibrillation (B); or $0.9 \%$ $\mathrm{NaCl} 1 \mathrm{ml} / \mathrm{kg}$ at 5 minutes and $0.5 \mathrm{ml} / \mathrm{kg}$ at 15 minutes of fibrillation (P). A total of 15 experiments were included for analysis. Arterial and venous blood gases were sampled at $4,8,13$, and 18 minutes of fibrillation. The SB group demonstrated the highest arterial partial pressures of carbon dioxide $\left(\mathrm{pCO}_{2}\right)$ at each sampling point after $\mathrm{NaHCO}_{3}$, including the 18-minute sample: $42 \pm 12$, $29 \pm 11$, and $35 \pm 10$ torr for SB, P, and B, respectively. In addition, SB produced arterial alkalemia $(\mathrm{pH}>7.45)$ after $\mathrm{NaHCO}_{3}$ administration. The arterial $\mathrm{pH}$ at 18 minutes of fibrillation for SB, $\mathrm{P}$, and $\mathrm{B}$ was $7.46 \pm 0.14,7.29 \pm 0.07$, and 7.41 \pm 0.1 , respectively. Similar trends for $\mathrm{pCO}_{2}$ and $\mathrm{pH}$ were observed for venous samples. Early, frequent administration of low-dose $\mathrm{NaHCO}_{3}$ during $\mathrm{CPR}$ is associated with elevated $\mathrm{pCO}_{2}$ and $\mathrm{pH}$ (alkalotic) values that may be potentially detrimental in this setting. It appears that this mode of administration offers no advantage over $B$ with regard to blood gas values during CPR in this canine model.

(Pharmacotherapy 1994;14(1):95-99)

During cardiac arrest and cardiopulmonary resuscitation (CPR), acidemia develops as a result of decreased oxygen delivery to the tissues, which leads to lactate production from anaerobic metabolism and tissue acidosis. The accumulation of lactate and the increased carbon dioxide

From the College of Pharmacy, University of Michigan, and Department of Pharmacy Services, University of Michigan Hospitals, Ann Arbor, Michigan (all authors).

Presented in part at the American College of Clinical Pharmacy winter practice and research forum, Ft. Lauderdale, Florida, February 7-10, 1993.

Address reprint requests to Barry E. Bleske, Pharm.D., College of Pharmacy, University of Michigan, Ann Arbor, MI 48109-1065. concentrations contribute to the metabolic and respiratory acidemia.

Potential complications of profound acidemia during CPR are depressed myocardial contractility, a lowered ventricular fibrillation threshold, an increased ventricular defibrillation threshold, and attenuation of catecholamine effectiveness. ${ }^{1-6}$ The current treatment of systemic acidemia that is not corrected by adequate ventilation is intravenous bolus injection of sodium bicarbonate $\left(\mathrm{NaHCO}_{3}\right) 1$ $\mathrm{mEq} / \mathrm{kg}$ followed every 10 minutes by 0.5 $\mathrm{mEq} / \mathrm{kg}{ }^{7}$ However, complications associated with standard bolus doses of $\mathrm{NaHCO}_{3}$ include hypercarbia, intracellular acidosis, and alkalemia. 
What is not known is whether or not these complications may be attenuated by altering both the timing and the method of drug delivery.

Standard administration of $\mathrm{NaHCO}_{3}$ results in a high concentration of drug in an environment containing high concentrations of hydrogen ions, which results in alkalemia and increases partial pressure of carbon dioxide $\left(\mathrm{pCO}_{2}\right)$. This may potentially be avoided by administering small, frequent, bolus doses early in the resuscitation period. This may allow $\mathrm{NaHCO}_{3}$ to counteract the increase in hydrogen ions when concentrations are lower without overwhelming the system, and may avoid the need for large doses later. In addition, early administration of small doses may attenuate the increase in $\mathrm{pCO}_{2}$ and allow the excess to be eliminated by ventilation. Therefore, we attempted to determine if an alternative mode of $\mathrm{NaHCO}_{3}$ administration (small frequent doses early during resuscitation) has beneficial effects on blood gas values.

\section{Materials and Methods}

Thirteen dogs that had previously undergone an episode of cardiac arrest with CPR were evaluated in a randomized fashion (random numbers in blocks of 3). Data analysis was performed in a blinded manner. The study was approved by the Unit for Laboratory Animal Medicine.

Before instrumentation, a forelimb vein was cannulated and surgical anesthesia was produced by intravenous injection of pentobarbital 25 $\mathrm{mg} / \mathrm{kg}$. The depth of anesthesia was routinely assessed, and supplemental pentobarbital $5 \mathrm{mg} / \mathrm{kg}$ was administered every 30 minutes as required. Each dog was secured in a supine position on a surgical table with a thermoblanket to maintain a body temperature of $37^{\circ} \mathrm{C}$.

A cuffed endotracheal tube was placed, with respirations controlled by an Ohio Anesthesia Ventilator (Ohio Medical Products, Madison, WI) with a fraction of inspired oxygen $\left(\mathrm{fiO}_{2}\right)$ of 1.0. Respirations were initiated at a rate of 15 breaths $/$ minute with a tidal volume of $15 \mathrm{ml} / \mathrm{kg}$. The ventilatory rate and tidal volume were adjusted to achieve and maintain an arterial $\mathrm{pH}$ of $7.40 \pm 0.05$ and a $\mathrm{pCO}_{2}$ of $40 \pm 5$ torr.

Blood samples were analyzed using a Radiometer ABL2 (Acid-Base Laboratory, Cleveland, $\mathrm{OH}$ ) within 5 minutes of sampling. Samples not immediately analyzed were stored in ice and analyzed within 30 minutes. Arterial (aortic) samples were collected through a pigtail catheter inserted into the femoral artery and positioned with its tip in the aortic arch. Venous blood samples were collected through a $6 \mathrm{~F}$ catheter inserted into the right jugular vein and positioned with its tip in the right atrium.

Aortic and right atrial pressures were measured through the pigtail catheters. All pressures were measured with a Gould P23 pressure transducer (after calibration), displayed on a monitor, and recorded by a Gould 8-channel RS 3800 graphic recorder (Gould Inc., Cleveland, $\mathrm{OH}$ ). The position of each catheter was determined by evaluating the pressure waveform and confirmed at the end of the experiment by autopsy. After catheter placement all dogs were anticoagulated with intravenous heparin $150 \mathrm{U} / \mathrm{kg}$ to ensure catheter patency. A three-lead surface electrocardiogram (ECG) was also continuously monitored and recorded.

After stabilization of arterial $\mathrm{pH}$ and $\mathrm{pCO}_{2}$, ventricular fibrillation was induced using a pacing wire carrying a $24-\mathrm{mA}, 60-\mathrm{Hz}$ electrical current placed through a $6 \mathrm{~F}$ catheter with its tip in the right ventricle. Ventricular fibrillation was confirmed by ECG pattern and loss of arterial pressures. After 3 minutes of unassisted cardiac arrest, CPR was begun using a pneumatic chest compression device (Thumper; Michigan Instruments, Grand Rapids, MI) set at a compression rate of 80 /minute with a compression duration of 0.5 seconds. The compression force was adjusted to produce a coronary perfusion pressure gradient (aortic-right atrial middiastolic pressure) of approximately $20 \mathrm{~mm} \mathrm{Hg}$. After every fifth compression, diastole was prolonged by 0.5 seconds and the lungs were inflated with an inspiratory pressure setting of approximately 10 $\mathrm{cm} \mathrm{H}_{2} \mathrm{O}$ and $\mathrm{fiO}_{2}$ of 1.0 .

After 5 minutes of ventricular fibrillation ( $2 \mathrm{~min}$ CPR), the animals were randomly assigned to one of three treatment groups: $\mathrm{NaHCO}_{3} 1 \mathrm{mEq} / \mathrm{kg}$ intravenous bolus over 20 seconds, followed by a second $0.5-\mathrm{mEq} / \mathrm{kg}$ bolus given at 15 minutes of ventricular fibrillation (B); $\mathrm{NaHCO}_{3} 0.5 \mathrm{mEq} / \mathrm{kg}$ intravenous bolus over 20 seconds, followed by a $0.5-\mathrm{mEq} / \mathrm{kg}$ bolus at 10 and 15 minutes of ventricular fibrillation (SB); or $0.9 \% \mathrm{NaCl} 1 \mathrm{ml} / \mathrm{kg}$ intravenous bolus over 20 seconds, followed by a second bolus of $0.5 \mathrm{ml} / \mathrm{kg}$ given at 15 minutes of ventricular fibrillation $(P)$. All treatments were administered through an indwelling catheter in a forelimb vein. At 4, 8, 13, and 18 minutes of cardiac arrest, blood samples were simultaneously obtained from the aorta and right atrium to determine blood gas values.

Statistical analysis was performed using analysis 
Table 1. Blood Gases Before and During CPR

\begin{tabular}{|c|c|c|c|c|c|c|}
\hline \multirow{2}{*}{$\begin{array}{l}\text { Time } \\
\text { (min) }\end{array}$} & \multicolumn{6}{|c|}{ Treatment Group } \\
\hline & B & $\mathrm{SB}$ & $P$ & B & $\mathrm{SB}$ & $P$ \\
\hline & \multicolumn{3}{|c|}{$\mathrm{pHa}$} & \multicolumn{3}{|c|}{$\mathrm{pHv}$} \\
\hline 0 & $7.372 \pm 0.019$ & $7.400 \pm 0.034$ & $7.388 \pm 0.027$ & $7.334 \pm 0.025$ & $7.342 \pm 0.026$ & $7.350 \pm 0.034$ \\
\hline 4 & $7.446 \pm 0.058$ & $7.476 \pm 0.112$ & $7.416 \pm 0.040$ & $7.262 \pm 0.019$ & $7.307 \pm 0.058$ & $7.300 \pm 0.033$ \\
\hline 8 & $7.506 \pm 0.205$ & $7.498 \pm 0.156$ & $7.390 \pm 0.077$ & $7.278 \pm 0.081$ & $7.270 \pm 0.037$ & $7.242 \pm 0.072$ \\
\hline 13 & $7.408 \pm 0.143$ & $7.466 \pm 0.150$ & $7.366 \pm 0.067$ & $7.246 \pm 0.071$ & $7.240 \pm 0.042$ & $7.224 \pm 0.072$ \\
\hline \multirow[t]{2}{*}{18} & $7.408 \pm 0.104$ & $7.466 \pm 0.145$ & $7.295 \pm 0.071$ & $7.227 \pm 0.042$ & $7.232 \pm 0.056$ & $7.200 \pm 0.071$ \\
\hline & \multicolumn{3}{|c|}{$\mathrm{aPCO}_{2}$ (torr) } & \multicolumn{3}{|c|}{$\mathrm{vPCO}_{2}$ (torr) } \\
\hline 0 & $40.10 \pm 3.904$ & $37.62 \pm 2.410$ & $39.24 \pm 3.008$ & $43.58 \pm 6.445$ & $48.58 \pm 4.342$ & $46.42 \pm 7.443$ \\
\hline 4 & $29.18 \pm 5.206$ & $28.02 \pm 8.679$ & $30.48 \pm 5.528$ & $55.68 \pm 5.048$ & $52.72 \pm 9.077$ & $52.82 \pm 6.272$ \\
\hline 8 & $35.90 \pm 12.723$ & $36.50 \pm 8.858$ & $26.32 \pm 10.495$ & $64.84 \pm 15.457$ & $68.60 \pm 5.680$ & $54.14 \pm 15.847$ \\
\hline 13 & $30.78 \pm 12.479$ & $37.02 \pm 10.735$ & $27.60 \pm 8.660$ & $64.06 \pm 12.522$ & $72.45 \pm 7.233$ & $55.28 \pm 14.036$ \\
\hline \multirow[t]{2}{*}{18} & $34.62 \pm 10.084$ & $42.10 \pm 11.653$ & $29.05 \pm 11.181$ & $65.85 \pm 9.764$ & $74.02 \pm 5.874$ & $59.94 \pm 12.681$ \\
\hline & \multicolumn{3}{|c|}{$\mathrm{aHCO}_{3}(\mathrm{mEq} / \mathrm{L})$} & \multicolumn{3}{|c|}{$\mathrm{vHCO}_{3}(\mathrm{mEq} / \mathrm{L})$} \\
\hline 0 & $22.78 \pm 1.678$ & $22.98 \pm 2.956$ & $23.20 \pm 2.027$ & $22.54 \pm 2.458$ & $25.75 \pm 3.472$ & $24.92 \pm 3.200$ \\
\hline 4 & $19.62 \pm 2.273$ & $20.04 \pm 4.014$ & $19.14 \pm 1.674$ & $23.62 \pm 1.886$ & $24.07 \pm 4.881$ & $25.22 \pm 2.587$ \\
\hline 8 & $28.22 \pm 9.318$ & $27.82 \pm 6.672$ & $15.22 \pm 4.200^{\mathrm{a}}$ & $29.00 \pm 3.833$ & $30.82 \pm 3.657$ & $21.86 \pm 3.684^{a}$ \\
\hline 13 & $18.20 \pm 3.947$ & $25.88 \pm 4.655^{b}$ & $15.20 \pm 3.585$ & $26.46 \pm 1.923$ & $29.88 \pm 2.546$ & $21.60 \pm 3.004^{a}$ \\
\hline 18 & $20.86 \pm 2.456$ & $27.20 \pm 3.132$ & $13.88 \pm 5.432^{\mathrm{a}}$ & $26.38 \pm 1.348$ & $30.08 \pm 2.022$ & $22.32 \pm 2.298^{\mathrm{a}}$ \\
\hline
\end{tabular}

${ }^{a} p<0.05$, $P$ versus $B$ and $S B$.

${ }^{\mathrm{b}} \mathrm{p}<0.05$, SB versus $B$ and $P$.

of variance (ANOVA) with a repeated measures design. Differences among means were evaluated using Tukey's Studentized range test with a $p \leq 0.05$ considered significant. Data are reported as means $\pm \mathrm{SD}$.

\section{Results}

Data suitable for analysis were obtained from 15 drug trials (experiments) in the 13 animals. Prior to breaking the randomization code, data from one trial in each of the treatment groups were excluded from analysis because of a decreased baseline aortic oxygen saturation greater than 2 SD from the population mean. Since all animals had a prior episode of cardiac arrest and CPR of similar duration $(10 \mathrm{~min})$, a decrease in aortic oxygen saturation could be an indication of underlying pathology, and therefore data from these animals were excluded. Five animals were evaluated in a crossover fashion, having been randomized to a different treatment arm after successful resuscitation. These were the only animals that were successfully resuscitated after $\mathrm{NaHCO}_{3}$ administration.

In addition to baseline blood gas values, baseline and CPR hemodynamics were evaluated to ensure that the animals were comparable among groups. No significant differences were seen in baseline arterial systolic or diastolic pressures among the three groups: B $122 \pm 30 \mathrm{~mm} \mathrm{Hg}$ (range 80-160 $\mathrm{mm} \mathrm{Hg}$ ) and $89 \pm 30 \mathrm{~mm} \mathrm{Hg}$ (range 60-130 $\mathrm{mm}$ $\mathrm{Hg}$ ); SB $116 \pm 19 \mathrm{~mm} \mathrm{Hg}$ (range $85-135 \mathrm{~mm} \mathrm{Hg}$ ) and $93 \pm 17 \mathrm{~mm} \mathrm{Hg}$ (range $65-110 \mathrm{~mm} \mathrm{Hg}$ ); and P $99 \pm 38 \mathrm{~mm} \mathrm{Hg}$ (range $50-135 \mathrm{~mm} \mathrm{Hg}$ ) and 80 $\pm 37 \mathrm{~mm} \mathrm{Hg}$ (range $30-115 \mathrm{~mm} \mathrm{Hg}$; $>0.50$ ). In addition, no significant difference was seen in coronary perfusion pressures after drug administration; at 5 minutes of ventricular fibrillation for B, SB, and P they were $19 \pm 9,23 \pm$ 8 , and $23 \pm 12 \mathrm{~mm} \mathrm{Hg}$, respectively ( $>>0.78$ ).

The mean arterial and right atrial $\mathrm{pH}, \mathrm{pCO}_{2}$, and $\mathrm{HCO}_{3}$ measurements during $\mathrm{CPR}$ are shown in Table 1. There were no statistically significant differences in either $\mathrm{pH}$ or $\mathrm{pCO}_{2}$ among groups at baseline or after $4,8,13$, and 18 minutes of CPR. No significant difference in the arteriovenous $\mathrm{pH}$ gradient was detected; however, arterial alkalemia ( $\mathrm{pH}>7.45$ ) occurred intermittently at times after drug administration in both $\mathrm{NaHCO}_{3}$ groups compared with arterial acidemia $(\mathrm{pH}<7.35)$ in the $\mathrm{P}$ group. In addition, the $\mathrm{SB}$ group had the greatest elevation in $\mathrm{pCO}_{2}$ values at all times measured after drug administration.

Prior to inducing cardiac arrest and at 4 minutes of ventricular fibrillation, the arterial and venous bicarbonate concentrations in all groups were similar. After 8 minutes of ventricular fibrillation, both the arterial and venous concentrations were significantly higher in animals randomized to the $B$ and SB groups compared with placebo $(p<0.05)$. 
After 13 minutes of ventricular fibrillation, the arterial bicarbonate level in the SB group remained significantly increased compared with the other two groups $(\mathrm{p}<0.05)$. However, in both $\mathrm{B}$ and $\mathrm{SB}$ groups it was again significantly increased above $P$ at 18 minutes $(\mathrm{p}<0.05)$.

\section{Discussion}

Similar to results from other investigations, the current study demonstrated that systemic acidemia develops during CPR. ${ }^{8}, 9$ To simulate CPR technique, aggressive ventilation was maintained, and the arterial $\mathrm{pCO}_{2}$ decreased by approximately 10 torr at 4 minutes in all groups. This degree of arterial hypocarbia was maintained in the placebo group until the end of the CPR period. However, after $\mathrm{NaHCO}_{3}$ administration, it increased in both treatment groups, being highest in the SB group at the end of CPR ( $>0.05)$.

Despite the failure to demonstrate a statistically significant difference in $\mathrm{pCO}_{2}$ among the groups, there appeared to be a trend to an overall higher value in the $\mathrm{NaHCO}_{3}$ groups, as discussed previously. This result is not unexpected, since other studies reported significant increases in $\mathrm{pCO}_{2}$ after bicarbonate administration. ${ }^{10,11}$ Similarly, we found no statistically significant differences in $\mathrm{pH}$ values among the groups. However, arterial alkalemia did occur in both the $\mathrm{B}$ and $\mathrm{SB}$ groups after drug administration. A potential complication of this is enhanced glycolysis leading to increased lactic acid production and increased oxygen-hemoglobin binding. In addition, arterial alkalemia may result in lower coronary perfusion pressures after epinephrine therapy, compared with arterial acidemia. ${ }^{12}$

The guidelines for advanced cardiac life support promulgated by the American Heart Association do not support early, empiric administration of $\mathrm{NaHCO}_{3}$ during cardiopulmonary resuscitation. ${ }^{7}$ The rationale is that acidemia can be controlled by ventilation alone for a short period of time, and that $\mathrm{NaHCO}_{3}$ may be detrimental and produce arterial alkalemia and paradoxic intracellular and intracerebral acidosis secondary to increased $\mathrm{pCO}_{2}$. We observed no favorable effects for an alternative dosing method (SB group) on arterial or venous $\mathrm{pH}$ or $\mathrm{pCO}_{2}$ when administered early during $\mathrm{CPR}$. In fact, this method was associated with the greatest elevation in arterial $\mathrm{pH}$ and $\mathrm{pCO}_{2}$ at the end of CPR.

With a larger sample these differences may have become significant (type II error). For example, to detect a difference in $\mathrm{pCO}_{2}$, approximately seven more experiments would have to be done to detect a difference between placebo and SB $(\alpha=0.05$, $\beta=0.2$ ). Therefore, several low-dose boluses of $\mathrm{NaHCO}_{3}$ administered every 5 minutes early during CPR may be less desirable than the currently recommended method, secondary to increased $\mathrm{pCO}_{2}$ concentrations and the development of alkalemia.

In contrast to these results, another animal study suggested that alternative modes of $\mathrm{NaHCO}_{3}$ administration may be beneficial. A continuous infusion of $0.1 \mathrm{mEq} / \mathrm{kg} /$ minute increased venous $\mathrm{pH}$ without significantly increasing $\mathrm{pCO}_{2}$, compared with standard doses. ${ }^{8}$ In addition, there was no indication of cerebrospinal fluid acidosis for the continuous-infusion group. Further work in this area is necessary to determine if alternative modes of $\mathrm{NaHCO}_{3}$ administration may be beneficial during CPR.

The findings of the current study should be interpreted with caution since the duration of ventricular fibrillation and CPR was short, and intracellular $\mathrm{pH}$ and survival were not evaluated. The relatively small sample may have hindered our ability to detect significant differences among the treatment groups. In addition, the sampling scheme may not have allowed for the detection of peak increases in $\mathrm{pH}$ and $\mathrm{pCO}_{2}$, which may have demonstrated significant differences from the placebo group. Finally, the applicability of these results to humans during cardiopulmonary arrest is unknown.

Our results demonstrate that early, frequent administration of low-dose $\mathrm{NaHCO}_{3}$ during CPR is associated with elevated $\mathrm{pCO}_{2}$ and $\mathrm{pH}$ (alkalotic) values that may be potentially detrimental in this setting. From these results it appears that this mode of administration offers no advantage over standard-dose $\mathrm{NaHCO}_{3}$ as it relates to blood gas values during $\mathrm{CPR}$ in this canine model. Further studies will determine if alternate methods of $\mathrm{NaHCO}_{3}$ administration for correcting acidemia during CPR are beneficial.

\section{References}

1. Clancy RL, Cingolani HE, Taylor RR, Graham TP, Gilmore JP. Influence of sodium bicarbonate on myocardial performance. Am J Physiol 1967;212:917-23

2. McElroy WT, Gerdes AJ, Brown EB. Effects of $\mathrm{CO}_{2}$, bicarbonate and $\mathrm{pH}$ on the performance of isolated perfused guinea pig hearts. Am J Physiol 1958;195:412-16.

3. Gerst PH, Fleming WH, Malin JA. A quantitative evaluation of the effects of acidosis and alkalosis upon ventricular fibrillation threshold. Surgery 1966;59:1050-60.

4. Kerber RE, Sarnat W. Factors influencing the success of ventricular fibrillation in man. Circulation 1979;60:226-30. 
5. Korstanje C, Mathy MJ, van Charldorp K, de Jonge A, van Zwieten PA. Influence of respiratory acidosis or alkalosis on pressor responses mediated by alpha- 1 and alpha- 2 adrenoceptors in pithed normotensive rats. Naunyn Schmiedebergs Arch Pharmacol 1985;330:187-92.

6. de Hurtado MCC, Argel MI, Cingolani HE. Influence of acidbase alterations on myocardial sensitivity to catecholamines. Naunyn Schmiedebergs Arch Pharmacol 1981;317:219-24.

7. American Heart Association Emergency Cardiac Care Committee and Subcommittees. Guidelines for cardiopulmonary resuscitation and emergency cardiac care. JAMA 1992;268:2199-2241.

8. Bleske BE, Chow MSS, Zhao H, Kluger J, Fieldman A. Effects of different dosages and modes of sodium bicarbonate administration during cardiopulmonary resuscitation. Am J Emerg
Med 1992;10:525-32.

9. Guerci AD, Chandra N, Johnson E. Failure of sodium bicarbonate to improve resuscitation from ventricular fibrillation in dogs. Circulation 1986;74(suppl IV):IV-75-9.

10. Federiuk CS, Sanders AB, Kern KB, Nelson J, Ewy GA. The effect of bicarbonate on resuscitation from cardiac arrest. Ann Emerg Med 1991;20:1173-7.

11. Gazmure RJ, von Planta M, Weil MH, Rackow EC. Cardiac effects of carbon dioxide-consuming and carbon dioxidegenerating buffers during cardiopulmonary resuscitation. J Am Coll Cardiol 1990;15:482-90.

12. Paradis NA, Goetting MG, Rivers EP, et al. The effect of $\mathrm{pH}$ on the change in coronary perfusion pressure after epinephrine during CPR in human beings [abstr]. Ann Emerg Med 1990;19:457. 